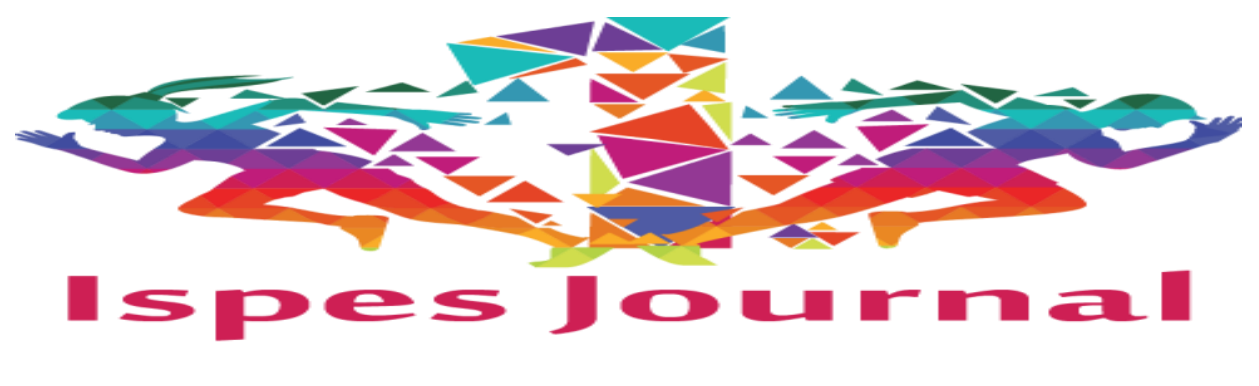

ISSN:2667-4777 Yıl:2, Sayı:2, Aralık 2019, s.1-12

T.C.

KASTAMONU ÜNIVERSITESİ

BEDEN EĞITIMIMI VE SPOR YÜKSEKOKULU

BEDEN EĞİTIMİ VE SPOR ÖĞRETMENLİĞİ ÖĞRETMENLİĞİ BÖLÜMÜ

KASTAMONU ÜNIVERSITESİ ÖĞRENCILERININ ZUMBA KATILIMLARI İLE

İLGILİ GÖRÜŞLERİ

YAZARLAR

Duygu GÖK

Ayşe Feray ÖZBAL

Derya AK 


\section{Kastamonu, 2019}

\section{Özet}

Yapılan bu araştırmanın amacı Kastamonu Üniversitesi Beden Eğitimi ve Spor Yüksekokulu nda ve diğer fakültelerde okuyan öğrencilerin zumba ile ilgili görüşlerini belirlemeye çalışmaktır. Çalışmaya Kastamonu Üniversitesi Besyoda öğrenim gören 21 öğrenci, diğer fakültelerde okuyan 16 katılmıştır. Çalışmada katılımcılarla 6 haftalık uygulama süreci gerçekleştirilmiştir. (13.11.2018-26.12.2018) Araştırma basit seçkisiz örneklem yöntemi kullanılmıştır. Araştırma yöntemi olarak zumbaya yönelik uygulama yapılmış olup seans öncesi ve seans sonrası görüşmeler ses kaydı ile alınıp dökümanları yapılmıştır. Verilerin içerik analizi yöntemi ile analiz edilmiştir. Araştırmanın sonucunda her iki grubunda zumbadan keyif, mutluluk aldığı, stres attığı, sosyalliğe etki ettiği, motivasyon sağladığg söylenebilir. Ayrıca hobi düzenli aktivite sağladığı, toplum içinde dans ederken özgüven kazandığı, bazılarının zorlandığı sonucuna varılabilir.

Anahtar Kelimeler: Zumba, Beden Eğitimi, Dans

\section{Abstract}

The aim of this study is to determine the students' opinions about zumba in Kastamonu University School of Physical Education and Sports and other faculties. The study included 21 students from Kastamonu University in Besyo and 16 from other faculties. 6-week implementation process was carried out with the participants (13.11.2018-26.12.2018). A simple random sampling method was used. As a research method, the application was made for 
zumbaya and pre-session and post-session interviews were taken with audio recording.Data were analyzed by content analysis method.As a result of the research, it can be said that both groups enjoy pleasure, happiness, stress, sociality and motivation in both groups. It can also be concluded that the hobby provides regular activity, it gains self-confidence while dancing in the community, some of them are forced.

Keywords: Zumba, Physical Education, Dance

\section{Giriş}

Günümüzde insanların toplumsal, fiziksel, duygusal olarak gelişimini, grup çalışmalarının kolaylaştırılması, toplum üyeliğinin kazanılması ve dayanışmanın karşılıklı sağlanmasının en kolay yollarından biri spordur. Spor, insanlara bir kişisel ve sosyal kimlik hissi yanında grup üyeliği duygusu vermesi ile insanların sosyalleşmesine yardımcı olan kavramdır ve fiziksel aktiviteler bütünüdür (Küçük \& Koç, 2004). Yapılan bir araştırmada ise spordan şöyle bahsedilmektedir: Spor, bireysel ve toplumsal olup bireylerin motorsal, bedensel ve zihinsel performanslarını ortaya koydukları etkinliklerdir (Kuru \& Karabulut, 2009). Yapılan bu etkinlikler insanların fiziksel ve zihinsel olarak rahatlamalarına yardımcı olmaktadır. İnsanlar zamanları, ilgileri ve ekonomik şartları doğrultusunda farklı branşlara yönelmektedir. Bunlardan bir tanesi de sporu en keyifli hale getirildiği düşünülen danstır.

Dans, insanın duygu ve düşüncelerini bedensel birtakım hareketlerle müzik eşliğinde ifade ettiği aktivitedir. Etnoloji Sözlüğü'nde ise kültürel olarak belirlenmiş olup belirli zaman ve mekanda özel hareket yapı ve anlam sistemi içinde insanın bedenini kullanması olarak geçer (Ayyıldız, 2016). Bireyin kendisini anlatma ve ifade etmesi, iç dünyasını dışa yansıtması ve bunları yaparken hareketleri kullanmasıdır (Cantekin, 2011). Diğer bir tanıma göre insanın ruhsal durumunu bedensel hareketlerle açığa vurmasıdır (Aydın, 2003). Geçmişten günümüze kadar insanlar duygu, düşünce, bilgi ve tecrübelerini dans yoluyla aktarmış ve onu bir ifade arac1 olarak görmüşlerdir (Yanık, 2010). Paulson dans1, "iletişim kurmak, anlamak, hissetmek için hareketin bir araç olduğu bir sanat dalı" olarak tanımlamaktadır (Özevin, 2006). İnsanların daha önceki yıllarda yoğun olan düşüncesi sporun dar salonlarda ve fitness aletlerinin arasında yapıldığını düşünmeleridir. Ancak ilerleyen teknoloji ve ülkemize farklı branşlarla gelen insanların bunları iyi tanıtmaları ve reklam yapmalarıyla birlikte insanlar, kendilerine uygun 
olan farklı branşlara katılmaya başlamışlardır. Özellikle kadınların dans, yoga, zumba vb. gibi branşlara son yıllarda ilgisinin artmaya başladığ söylenebilir.

Sporun alt dallarından biri olan dansın fiziksel gelişmeye, rahatlamaya ve fiziksel terbiyeye katkı sağlayan bedensel bir aktivite olduğu söylenebilir. Sıçrama, uzanma, koşma, sekme, çökme, dönme vb. hareketler ile vücudun kinesiyolojik organlarını çalıştırdığı için beden gelişimine katkı sağlar. Diğer sporlarda olduğu gibi dansın sonunda da fiziksel gerginliğin atılarak rahatlamaya ulaşıldığı düşünülmektedir (Eroğlu, 2017). Dans sporla iç içe olan bir kavramdır birçok alanla ilişkilendirilebilir. Bunlardan bir tanesi de egzersizdir.

Egzersiz, doğumdan ölüme kadar devam eden süre zarfında bireyin fiziki yapısını ve psikolojisini geliştiren aktivite süreçleri olduğu bilinmektedir (Nahçivan, 1994). Egzersizin insanın beden ve ruhsal sağlığına olumlu etkide bulunduğu bilindiği halde buna rağmen ülkemizde egzersiz yapanların sayısının az olduğu söylenebilir. Ancak günümüzde son zamanlarda insanlar bu konuda bilinçlenmeye başlamıştır ve hayatın monotonluğundan kurtuldukları, eğlenerek de egzersiz yapabildikleri farklı branşlara yönelmişlerdir. $\mathrm{Bu}$ branşlardan birinin de zumba olduğu söylenebilir.

Zumba heyecan verici, mutlu, enerjik ve latin müziğini dünya müziği ve dans hareketleriyle bütünleştiren, latin dünyasından esinlenerek etkili bir fitness programı oluşturan bir dans fitness dersidir. Zumba, aerobik ve fitness yaklaşımını kullanarak kardiyo ve kas güçlendirme egzersizlerinin bedene dinamiklik ve biçim kazandıran hızlı ve yavaş ritimlerden oluşur. Zumbanın kalori tüketimini üst düzeye çıkardığı söylenebilir (zumba, Zumba Eğitmenlik Kılavuzu Zumba Temel Aşamalar 1. Seviye, 2018).

Aksiliklerden çıkan büyük fikirler vardır. Beto PEREZ Kolombiyalı fitness eğitmenidir. Her zamanki derslerine getirdiği aerobik müziklerini unuttuğunu fark eder. $O$ sirada çantasındaki kendisi için hazırladığ karışık salsa, merengue şarkılarının bulunduğu kaseti alır ve dersinde bu kaseti kullanır. Beto enerjisi ile kendine ait koreografilerle dersini verir ve herkes bu derse hayran kalır. Böylelikle dans fitness doğmuş olur. Zumba fitness-party 2001 yılında Beto PEREZ dans fitness egzersizini Miami’ye getirmiştir. Daha sonra Beto PEREZ Kolombiyalı iki arkadaşı ile zumba fitness ismini vererek şirket oluşturmuşlardır. 2009 yılında Beto PEREZ Türkiye de düzenlediği Masterclass ile zumba fitness '1 tanıtmıştır (http-2).

Bir zumba fitness seansinın merenge, salsa, reggaeton ve cumbia dans stilleri olmazsa olmazıdır. 1 saat süren zumba fitness seansı 1sınma şarkısı ile başlar. Daha sonra intermittent(aralıklı) egzersiz olacak şekilde şarkılar sıralanır ve soğuma müziği ile zumba fitness seansı biter. Parti havasında geçen seanslar sayesinde insanların egzersiz yapmaktan 
sıkılmadığ1 söylenebilir. Yüksek enerjili geçen 1 saatlik ders süresinde yaklaşık olarak 600-650 kalori harcanır (Http2). Zumbanın Temel Aşamaları aşağıdaki gibidir:

MERENGE: Merenge kökeninin Dominik Cumhuriyetine uzandığ 1 bilinse de birçok Latin Amerika ülkesinin bu ritim de stil uyarlamaları vardır. 120-160 vuruşlu hızlı tempolu bir ritimdir ve her vuruşun ağır ve eşit bir vurgusu bulunur.Tambur, Kongo davulu, Mambo trompeti ve guiro enstrümanları yaygın olarak bulunur (Http1).

SALSA: Küba, Porto Riko ve Afrika'nın etkisi altında kalarak birçok kültür ile harmanlanmıştır. Timbal, Klave, Konga, Trombon, Trompet yaygın enstrümanlar arasında yer alır. Müzik vuruşu çok kolay ayırt edilir (Http1).

CUMBİA: Afrika ve Avrupa etkileri taşımakla birlikte Güney Amerika ve Kolombiya ritmi olarak bilinir. Tropikal ve Kreol esintisi bıraktığı müzik üzerinde bilinir. Guiro, akordeon ve tamburu içerir ve perküsyon, kilit bir enstrüman grubudur (Http1).

REGGAETON: Porto Riko ile Panamada halk arasında yaygın olup Jamaika etkisi taşır. Ağır bir bas davulu vuruşundan oluşur. Temel enstrümanı Reggae tarzında davuldur (Http1).

Dans meraklısı olsun veya olmasın herkes Zumba derslerini kolaylıkla öğrenir. Dans tecrübelerinin olmasına gerek yoktur. Zumba dersiyle eğlenceli bir ortam oluşur ve egzersize yeni başlayan veya daha önce sosyal grup egzersizlerine tereddütle yaklaşanların gözlerinde büyütülemeyecekleri firsat verilir. Daha önce egzersiz yapmış kişiler için ise sağlıklı, mutlu ve enerjik egzersiz yaptıklarından ötürü memnuniyetle karşıladıkları söylenebilir. Zumbanın yararları ise şu şekilde sıralanabilir (Http1):

-Karın ve arka bel egzersizlerinde mükemmel dinamiklik.

-Şiddetli kalori yakımı sağlar. Kişinin beslenmesine, yoğunluk düzeyine vs. değiş̧iklik gösterebilir.

-Kolay, mutluluk veren ve parti havasinda dans hareketleri sunulur.

-Dengeli bir beslenme ile kilo verilmesini hızlandırır.

-Kişinin kendisini daha iyi hissetmesini sağlar.

-Bedenin tüm bölümlerinin şekillenmesinde yardımcı olur.

Türkçe literatür tarandığında zumba ile ilgili yapılan çalışmaların yok denecek kadar az olduğu görülmektedir. Ülkemizde yeni yeni gelişen bu branşın faydalarını ve kişiler üzerindeki etkilerini belirlemek amaciyla Kastamonu Üniversitesi öğrencileri ve Beden Eğitimi ve Spor 
Yüksekokulu öğrencilerine uygulama yapılarak kişilerin düşüncelerini ortaya koymak hedeflenmektedir.

\section{Yöntem}

Yapılan bu araştırma nitel yaklaşımı temel alarak yapılmıştır. Araştırmada örneklem yöntemi olarak basit seçkisiz örnekleme yöntemi kullanılmıştır. Basit seçkisiz örneklem: Evrenden örneklem için şeçkisizlik ilkesine uygun olarak birim çekme işleminin yapıldı̆̆ 1 örnekleme yöntemleridir(http3). Araştırmanın çalışma grubunu 2018-2019 y1lında Kastamonu Üniversitesi Besyo'da öğrenim gören 21 öğrenci( 7 kadın 14 erkek) ve diğer fakültelerden ise 16 öğrenci( 15 kadın 1 erkek) olmak üzere öğrenim gören toplam 37 öğrenci oluşturmaktadır. Araştırma 6 haftalık bir uygulama sürecini içermektedir. Diğer fakülte öğrencilerinin isteği üzerine erkek öğrenciler besyo grubuna dahil edilerek uygulama yapılmıştır. Yapılan bu araştırmada uygulamalar gönüllülük esasına dayanılarak yapılmıştır. Uygulama öncesi gönüllülük formu ve sağlık formu imzalatılmıştır. Bu uygulama Besyo ve Diğer fakülte öğrencilerine iki grup olarak farklı günlerde yapılmıştır. Uygulama öncesi ve sonras1 öğrencilerle yarı yapılandırılmış görüşmeler gerçekleştirilmiştir. Görüşme soruları araştırmacılar tarafından hazırlanmış ve uzman görüşü alınarak sorulara son şekli verilmiştir. Elde edilen görüşme cevaplarının düzenli olarak dokümanları yapılmıştır. Veriler içerik analizi yöntemiyle analiz edilmiştir. Çalışma etiği gereği katılımcıların gerçek isimleri çalışmada kullanılmamış kod isimler kullanılmıştır. İçerik analizi belirli karakterler baz alınarak metin içerisinde sistematik sonuçlar üretilmesinde kullanılan yöntemdir (Yıldırım, Yıldırım, \& Çelik, 2018).Verilerden temalar ve alt temalar oluşturulmuş bulgular ona göre yorumlanmıştır.

\section{Bulgular}

Araştırmadan elde edilen bulgular diğer fakülte öğrencilerinden elde edilen bulgular ve Beden Eğitimi ve Spor Yüksekokulu öğrencilerinden elde edilen bulgular olarak 2 başlık altında incelenmiştir.

Beden Eğitimi ve Spor Yüksekokulu öğrencilerinden elde edilen verilere iliş̧kin bulgular:

Zumbanın eğlenceli ve keyifli olduğu ile ilgili 'Çok eğlenceliydi. Gayet keyif aldım. Kesinlikle keyif aldım (Ö:1, Ö:16).’ cevaplarına ulaşılmıştır. 
Zumbanın kilo verme konusunda faydalı olduğu ile ilgili 'Kilo vermeye başladım. Kilo verme açısından fayda gördüm (Ö16,Ö17).' Cevaplarına ulaşılmıştır.

Zumbanın hem stres atma hem de yorgunluk olduğuna dair 'Ruhen kendimin geliştiğini ve rahatladığını hissettim, fiziken vücudumun aktif olduğunu hissettim. Fiziksel olarak yorucuydu, ruhsal olarak zevkliydi. Bedensel kendimi yorgun hissettim. Ruhen gayet keyifliydi(Ö:1, Ö:4).’ Cevaplarına ulaşılmıştır.

Zumba da zorlanmanın ve deneyimsizlik ile ilgili 'Çok kıvrak hareketler beni zorladı. Koreografiyi bilmemem. Hareketler biraz değişikti. Zumbada ya o figürler bilmediğimiz için onlar bizi biraz zorluyordu.' 'Pozitif oluyorum, çekingenlik olmuyor. Zumbaya bakış açım değişti özgüvenim arttı(Ö:4,Ö:3,Ö:12).' Cevaplarına ulaşılmıştır.

Zumbanın sosyallikte katkı sağladığı ile ilgili 'Sosyalleştim. Sosyalleşme konusunda bana birçok faydası oldu. Sosyallik anlamında hayatımı etkilediğini düşünüyorum(Ö:14,Ö:17,Ö:5).' cevaplarına ulaşılmıştır.

Zumbada öğrenme ve gelişme ile ilgili ' İlk seanstan sonra ki seans daha iyiydim. Ne gibi değişiklikler farklı bir dans türü farklı dans figürleri öğrendim(Ö:1,Ö:15)’ Cevaplarına ulaşılmıştır.

Zumbayı hobi olarak devam ettirileceği ile ilgili‘ Ara ara devam edebilirim hobi olarak. Profesyonel anlamda değil ama eğlence olarak yapabiliri(Ö:3, Ö:5).' Cevaplarına ulaşılmıştır.

Diğer Fakülte öğrencilerinden elde edilen verilere ilişkin bulgular:

Zumbanın keyifli ve eğlenceli olduğu ile ilgili ‘ Evet keyif aldım. Keyif aldım güzeldi. Benim için iyiydi çok eğlendim, mutlu oldum(Ö:1,Ö:11,Ö:7).' Cevaplarına ulaşılmıştır.

Zumbada dini inanç etkisi nedeniyle çekingenlik gösterilmesi ile ilgili bulgularda ise 'Dinin getirdiği kurallar nedeni ile yapamam. Yani biraz utanırım. Topluluk önünde dans etmek tabi ilk önce insanı utandırıyor ama sonra açılıyorsun. Kapalı olduğum için erkek olduğunda sıkıntı olurdu benim içim.' Cevaplarına ilişkin 'dini inanç, çekingenlik(Ö:11,Ö:5).' sonuçlarına ulaşılmıştır.

Zumbanın deneyim ve gelişme sağladığı ile ilgili‘ ‘llk seans hareketler konusunda bayağı zorlandım sonradan yapabildim hareketleri. Spora bakış açım değişti spor faaliyetine katılım sağladım. İlk defa zumbayı bu etkinlikte tanıdım(Ö:1,Ö:7,Ö:1).' Cevaplarına ulaşılmıştır. 
Zumbanın özgüven kazandırması ile ilgili‘ Topluluk önünde dans etmek özgüven ister. Benim tereddütüm yok hani ben dans edebilirim, yani kalabalık beni rahatsız etmiyor. Evet çevre arkadaş anlamında bana bayağı özgüven sağladı(Ö:12,Ö:1).' Cevaplarına ulaşılmıştır.

Zumbanın sosyallik anlamında katkı sağladığına dair 'Tanımadığım kişilerle dans ettim. $\mathrm{Bu}$ spor konularıyla ilgilenen arkadaşlarla aramızda daha yeni sohbet oldu(Ö:7,Ö:2).' Cevaplarına ulaşılmıştır.

Zumbada zorlanma ve deneyimsizlik ile ilgili 'Bazı hareketler vardı çok zordu. Bazı hareketler zorladı tabi. Yani bir dans var onu tam olarak bilmiyorum ama yapamadığım oldu. Evet ilk kez bir deneyimim olduğu için zorlandım(Ö:1,Ö:11,Ö:12).'Cevaplarına ulaşılmıştır.

Zumbanın hem stres atma hem yorgunluk olduğu ile ilgili 'Fiziken biraz yoruluyordum ama yorulmama değiyordu. Stres atmama yardımcı oldu. Çok stres azaltıcı kafamızı boşalttığımız için diğer işlerimize odaklanmamızı sağladı(Ö:12,Ö:6,Ö:3).' Cevaplarına ulaşılmıştır.

Araştırmacının günlüklerinde ise 'Diğer fakültelerden çok eksik vardı. Kişi sayısı bayağı azaldı. Besyoda ise kişi sayısı diğer fakültelere oranla yüksekti. Hatta yeni katılanlar bile oldu bugün. Diğer fakülte öğrencilerine ne yaptırdıysak coşturamıyoruz. Besyodaki enerjiyi yakalayamıyoruz.' gibi alıntılara vardır.

\section{Tartışma ve Sonuç}

Yapılan bu araştırma Beden Eğitimi ve Spor Yüksekokulu ve Diğer Fakülte öğrencilerinin zumbaya yatkınlığı ve zumbayı devam ettirme ilgileri belirlemek amacı ile çalışma yapılmıştır. Çalışmada Besyodan 21, diğer fakültelerden ise 16 öğrenci uygulamaya katılmıştır. Bu uygulama 6 haftalık süreci kapsamaktadır. Seans öncesi ve seans sonrası toplanan veriler içerik analizi yöntemi ile kodlanıp bir sonuca ulaşılmıştır. Yapılan araştırma sonucunda Besyo öğrencilerinin zumbadan keyif ve mutluluk aldığı, eğlendiği, stres attı̆ğ, kilo verdiği, özgüven ve deneyim kazandığı, sosyallik sağladığı, zumbayla yeni dans figürleri öğrenip gelişme gösterdiği ve onlara düzenli bir egzersiz ortamı oluşturduğu yapılan analizler sonucunda ortaya çıkmıştır. Literatür incelendiğinde zumba ile ilgili sınırlı sayıda çalışma olduğu görülmektedir. Yapılan bu araştırmalardan birinde ise pilates, crossFit zumba yapan kadınların vücut kompozisyonlarını incelemek amacıyla 12 hafta boyunca gönüllü olarak katılan kadınlara karma bir egzersiz yapılmıştır ve sonucunda vücut ağırlığı ve BKİ(Beden kitle indeksi) ön test ve son test arasında anlamlı bir fark bulunmuştur. Hem vücut ağırlığında hem de kadınların BKİ ortalamalarında bir azalma olduğu sonucuna ulaşılmıştır. Uygulanan egzersiz 
programı sonucunda kadınların vücut alanları memnuniyet ön test ve son test değerleri arasında anlamlı bir fark ortaya çıkmıştır (Baştuğ, Özcan, Gültekin, \& Günay, 2016). Dokuz Eylül Üniversitesi Buca Eğitim Fakültesi öğrencilerinin “Oyun, Dans ve Müzik “ dersinde yapılan yaratıcı dans etkinliklerinin motivasyon, beden dili, özgüven ve dansa ilişkin yeterlilik ve dans performansı üzerindeki etkilerini incelemek amacıyla 2011 yılında yapılmış olan 14 haftalık bir araştırma sonucunda yaratıcı dans etkinliklerinin müzik öğretmenleri adaylarının Oyun, Dans ve Müzik dersine ilişkin motivasyonları, özgüvenleri, beden dili ve dansa ilişkin öz yeterlilikleri ve dans performansları üzerinde anlamlı düzeyde etkili olduğu sonucuna ulaşılmıştır (Özevin \& Bilen, 2011). Bu sonuçların yapılan araştırmayı desteklediği görülmektedir.

Zumba egzersizini bazı öğrencilerin devam ettirebileceği bazılarının ise hobi olarak devam edeceği sonucu elde edilmiştir. Zumbaya olan ilgilerinde ise araştırmacı günlüklerinde ve gözlemlerinde pozitif oldukları ve branşa olan istekli olarak devamlılık sağladıkları görülmektedir. Diğer Fakülte Öğrencilerinin ise yapılan bu araştırma sonucunda keyif aldığı, eğlendiği, stres attığı, deneyim ve özgüven kazandığı, sosyalleştikleri ve gelişme gösterdikleri yapılan analizler sonucunda ortaya çıkmıştır. 2016'da yapılan bir araştırmada üniversite öğrencilerinin dans kavramına ilişkin algılarını, metaforlar aracılığıyla ortaya çıkarmak amacı ile araştırma yapılmıştır. Araştırma sonucunda ise dansın, bireylere özgürlük duygusu kattı̆ğ1, haz verdiği, özgüven sağladığı, mental olarak olumlu etkiler yarattığı, mutlu ettiği, stresten arındıran bir etkinlik olduğu katılımcılar tarafından belirtilmiştir (Ayyıldız, 2016). Diğer Fakülte Öğrencilerinde dini inancın getirmiş olduğu veya da topluluk önünde dans etmekten fazlasıyla çekindiği veri analizi kısmında keşfedilmiştir. Diğer fakülte öğrencilerinin zumbaya olan ilgileri ile ilgili zumbayı çok sevdikleri ve sürdürecekleri sonucuna ulaşılmıştır. Fakat araştırmacı gözlerine ve günlüklerinde seanslara çok nadir geldikleri ve devamlılık göstermedikleri görülmektedir. Her iki grubun da seans öncesinde çok zorlandıkları seans sonrası görüşmelerinde ise çok rahat bir şekilde uyum sağladıkları sonucuna da ulaşılmıştır. 2009 yılında yapılan diğer bir araştırmada ise 8 haftalık (haftada 3 gün, günde 60 dakika) aerobik dans egzersizlerinin kardiyovasküler verimlilik, toparlanma kalp atım hızı, kan basıncı, esneklik ve vücut ağırlı̆ğ üzerine etkileri araştırılmıştır. Araştırma sonucunda ise karditovasküler verimlilik, toparlanma kalp atımı, sistolik kan basıncı(büyük tansiyon), esneklik ve vücut ağırlıkları arasındaki farkın istatiksel açıdan anlamlı olduğu sonucu görülmüştür (Biçer, Yüktaşır, Yalçın, \& Kaya, 2009). Sonuç olarak zumbanın bireylerde olumlu etki yarattı̆̆1, bedenen ve zihnen fayda sağladığı söylenebilir. 


\section{Öneriler}

Öğrencilerin zumbaya olan ilgileri ve aldıkları pozitif enerji ön planda tutularak ilköğretim, ortaöğretim ve yükseköğretim derslerine motivasyon, ruh sağllğı ve beden sağlığ için yararlı olabileceği düşünülerek seçmeli ders olarak konulması ve uygulatılması düşünülebilir. Zumba ile ilgili etkinlikler yapılabilir ve sosyal sorumluluk projeleri için bir etkinlik olarak görülebilir. Özerk bir kurum olduğu için bir federasyona bağlanarak eğitimler açılabilir ve ülke içinde yaygınlaştırılabilir.

\section{Kaynakça}

Aydın, K. E.-S. (2003). Etnoloji Sözlüğü Ankara Bilim Ve Sanat Yayınevi. Ankara: Bilim Ve Sanat Yayınevi Ankara.

Ayyıldız, T. (2016). Üniversite Öğrencilerinin Dans Kavramına Yönelik Metaforik Algılarının Analizi. Gaziantep Üniversitesi Spor Bilimleri Dergisi, 13.

Baştuğ, G., Özcan, R., Gültekin, D., \& Günay, Ö. (2016). the effects of crossfit, pilates and zumba exercises on body composition and body image of women. international journal of sports exercise and training science, 1.

Biçer, B., Yüktaşır, B., Yalçın, H. B., \& Kaya, F. (2009). yetişkin bayanlarda 8 haftalık aerobik dans egzersizlerinin bazı fizyolojik parametreler üzerine etkisi. beden eğitimi ve sosyal bilimler dergisi, 1.

Büyüköztürk, D. D. $\quad(2012,5$ 14). 4 15, 2019 tarihinde google: http://w3.balikesir.edu.tr/ msackes/wp/wp-content/uploads/2012/03/BAY-Final-Konulari.pdf adresinden alınd1 (http-3,2019).

Cantekin, D. (2011, 7 15). Dansta Kullanılan Hareketlerle İlgili Terimlerin İncelenmesi. Sakarya.

Eroğlu, T. (2017). Dans Kavramı Ve Dansın İşlevi. Odak, 222. 
Kuru, E., \& Karabulut, E. O. (2009). Ritim Eğitimi ve Dans Dersi Alan ve Almayan Beden Eğitimi ve Spor Yüksekokulu Öğrencilerinin Problem Çözme Becerilerinin Çeşitli Değişkenler Bakımından İncelenmesi. Gazi Eğitim Fakültesi Dergisi , 4.

Küçük, V., \& Koç, H. (2004). Psikososyal Gelişim Süreci İçerisinde İnsan ve Spor İlişkisi. Dumlupınar Üniversitesi Sosyal Bilimler Dergisi, 2.

Nahçivan, N. (1994). Sağlıklı Yaşam İçin Egzersizin Önemi. Florence Nightingale Hemşirelik Dergisi, 1.

Özevin, B. (2006). Oyun Dans ve müzik dersine ilişkin motivasyon ölçeği. ulusal müzik eğitimi sempozyumu bildirisi, (s. 1). pamukkale üniversitesi eğitim fakültesi.

Özevin, B., \& Bilen, S. (2011). yaratıcı dans etkinliklerinin motivasyon özgüven özyeterlilik ve dans performansı üzerine etkileri. hacettepe üniversitesi eğitim fakültesi dergisi, 1.

Yanık, E. (2010, 6 28). Dans Ve İletişim. Sakarya: Sakarya Üniversitesi Sosyal Bilimler Enstitüsü.

yıldırım, A. (2018). sosyal bilimlerde nitel araştırma yöntemleri. ankara: seçkin.

Yıldırım, G., Yıldırım, S., \& Çelik, E. (2018). Yeni Bir Bakış Açısı 3 Boyutlu Yazıcılar ve Öğretimsel Kullanımı:Bir İçerik Analizi. Bayburt Eğitim Fakültesi Dergisi, 5.

Zeybek, D. (2019, 4 15). Zes Didem Zeybek. 4 15, 2019 tarihinde Googlee: http://www.zumbawithdidem.com/soru-cevap.html adresinden alınd1 ( http-2,2019).

zumba. (2018). Zumba Eğitmenlik Kılavuzu Zumba Temel Aşamalar 1. Seviye. zumba.com.(http-1,2019). 
